\title{
Nucleolar organiser regions and survival in patients with non-Hodgkin's lymphomas classified by the working formulation
}

\author{
J Jakić-Razumović, D Tentor, M Petrovečki, I Radman
}

\begin{abstract}
Aims-To correlate the numbers of silver staining nuclear organiser regions (AgNORs) in non-Hodgkin's lymphoma classified by the working formulation with survival, the first complete remission, and the length of remission.

Methods-Sixty one patients were included in the study. Paraffin wax sections were stained using silver solution to visualise nucleolar organiser regions. The AgNORs were counted in 150 nuclei of each specimen. Data were examined using the Kruskal-Wallis test, multivariate discriminant analysis, and Cox's regression test. Curves were calculated by the method of Kaplan and Meier.

Results-Most patients who were alive had low grade lymphoma $(p<0.01)$. The first complete remission was obtained more frequently in the low and intermediate grade groups $(p<0.05)$. The longest survival was found in the low grade group ( $p<0.001)$. The mean number of AgNORs differed significantly in all three groups $(p<0.001)$. This was also true for area of nuclei $(p<0.001)$ and length of remission $(p<0.05)$. In a multivariate analysis the numbers of AgNORs were highly predictive for survival, remission, and the length of remission.

Conclusions-The numbers of AgNORs correlated with survival, remission, and the length of remission in patients with non-Hodgkin's lymphoma.
\end{abstract}

(F Clin Pathol 1993;46:943-947)

Department of Pathology, Zagreb University School of Medicine and Zagreb Clinical Hospital, Zagreb, Croatia J Jakić-Razumović D Tentor

Department of Clinical Laboratory

Diagnosis

M Petrovečki

Division of

Haematology

I Radman

Correspondence to:

Dr Jasminka Jakić-

Dr Jasminka Jakic-

Razumovic, Fred

Hutchinson Cancer

Department of Pathology

Department of Pathology

SC 111, 1124 Columbia 2092, USA.

Accepted for publication

1 June 1993 developed to serve as predictors of the response to treatment and survival. ${ }^{2-10}$ Since Crocker and $\mathrm{Nar}^{11}$ and Crocker and $\mathrm{Egan}^{12}$ described the diagnostic value of the costing of nucleolar organiser regions (NORs) in tissue sections using the one-step silver staining technique, the prognostic value of this technique has been investigated in patients with NHL.

\section{Methods}

Seventy pre-treatment paraffin wax embedded biopsy specimens from 70 consecutive patients treated and followed up for nonHodgkin's lymphoma (NHL) in the Zagreb Clinical Hospital, Croatia, during 1980-1992 were studied. Nine patients were lost to follow up because for these patients only data about their first hospital stay were available. Therefore, these patients were excluded from the study. In fact, there was not sufficient information, suggesting that survival data were not available. Complete follow up histories were available for 61 patients (date of last clinical examination or date of death). Patients ranged in age from 13-74 years, with a mean age of 52.5 years. Mean age in the group of patients with low grade NHL was 55 (range 35-74) years, in the intermediate grade group 50 (range 13-79) years, and in the group with high grade NHL 52 (range 15-68) years. There were 44 men and 17 women. The follow up period ranged from 1 to 122 months (mean $46 \cdot 3$ months). Lymphomas were classified according to the working formulation system-low, intermediate, and high grade malignancy. ${ }^{13}$ All tumours studied had B cell markers (CD 45RA; Dakopatts, Copenhagen, Denmark) except four which had $T$ cell markers (CD 45RO; Dakopatts). All patients included in this study were treated in order of protocol schema, after histological diagnosis had been made. Patients with low grade NHL were treated with ACOP (adriamycin, cyclophosphamide, oncovin, prednisone), COP (cyclophosphamide, oncovin, prednisone), and Leukeran-Endoxan (chlorambucilcyclophosphamide) protocols because treatment changed during the study years. Most patients with intermediate grade NHL were treated with ACOP protocol, as well as all those with high grade NHL.

PREPARATIONS OF SPECIMENS FOR AgNORS STAINING AND COUNTING

All sections were cut at $3 \mu \mathrm{m}$ thickness from routinely processed paraffin wax blocks. These were dewaxed in xylene and hydrated through ethanol to deionised water. Two volumes of a $50 \%(w / v)$ aqueous solution of 
$\mathrm{AgNO}_{3}$ were mixed with one volume of $2 \%$ $(\mathrm{w} / \mathrm{v})$ gelatine in $1 \%(\mathrm{w} / \mathrm{v})$ formic acid. The staining solution was prepared immediately before use, placed on the sections, and allowed to react in the dark for 30 minutes at room temperature. The slides were then washed with deionised water, dehydrated to xylene, and mounted in a synthetic medium. No counterstain was used. The AgNORs were counted in 150 nuclei of each specimen using a $\times 100$ oil-immersion lens as described by Egan $e t a l^{14}$ and Howat $e t a l^{15}$ with a standard interactive microprocessor computer assisted image analysing system (Aristoplan, Olympus, Japan, IBM compatible computer and EMAS-software, Zagreb) and a graphic monitor.

The data were studied on an IBM-PC compatible computer by use of the Number Cruncher Statistical System (NCSS, Kaysville, Utah, USA). Survival was calculated from the start of treatment to the last follow up date or death. The length of remission was defined as the interval between the confirmed establishment of the first complete remission (CR) and the date of documented relapse. The clinicopathological relations of the mean AgNORs number and other variables were examined using the $\chi^{2}$ test and the non-parametric Kruskal-Wallis test. ${ }^{16}$ Multivariate Cox's proportional hazard regression model was performed as a forward stepwise variable selection into the final model equation, according to $\chi^{2}$, greater than or equal to $4 .{ }^{17}$ Multivariate discriminant analysis was performed to examine factors which independently predict the histological grade of NHL and responder or non-responder classes as a group variable. Forward stepwise variable selection into the final equation was used, according to $p$ value of $F$ ratio less than or equal to $0 \cdot 05 .^{18}$ Both methods can analyse ordinal variables as well as nominal (categorical) such as gender; clinical stage (binary split of stages I + II and III + IV as dummy variable); presence of $B$ symptoms (yes/no as dummy variable); and histological type (grades coded as 1, 2, and 3). Regression coefficients were calculated using the method of Schmee and Hahn for fitting linear regression model to censored data. ${ }^{18}$ Actuarial survival probability curves were calculated according to the method of Kaplan and Meier and compared by log-rank test. ${ }^{18}$

\section{Results}

Table 1 shows general characteristics for the whole series of 61 patients divided into the three groups according to the working formulation of NHL. There was no significant difference in sex distribution. Most patients who were alive had low grade lymphoma while most of those with high grade lymphoma were dead $(p<0.01)$. We found no significant associations with clinical stage, B symptoms, and relapse of disease. The length of remission differed significantly $(p<0.05)$. Most patients in the low and intermediate grade groups had complete remission while most of those in the high grade group had no remission. Survival rate was longest in the low grade and the shortest in the high grade group ( $p<0.001)$. Actuarial survival of all 61 patients is shown in figure 1 . The survival period differed significantly among the three groups according to the working formulation of NHL ( $p<0.01$ ) (fig 2 ).

Nuclei of low grade lymphoma cells contained AgNORs in the range 1.21-2.52 (mean 1.54); those of intermediate grade $1 \cdot 72-4.15$ (mean 2.92); while for those in the high grade group the range was $3 \cdot 81-5 \cdot 22$ (mean 4.57) AgNORs (fig 3) (table 1). The mean number of AgNORs differed significantly in all three groups $(p<0.0001)$ as well as the area of nuclei $(p<0.001)$.

Data in table 2 show a multivariate analysis of clinical and histological variables with respect to the histological type of tumour and three clinical outcomes: actuarial survival; achievement; and length of remission. A multivariate analysis was performed to examine primary predictive factor(s) that indepen-

Table 1 Clinical and histological features (with statistical parameters and survival analysis) of 61 patients with NHL, according to the working formulation

\begin{tabular}{|c|c|c|c|c|}
\hline \multirow[b]{2}{*}{ Variable } & \multicolumn{3}{|c|}{ Working formulation } & \multirow[b]{2}{*}{ p Value } \\
\hline & $\operatorname{Low}(n=21)$ & Intermediate $(n=29)$ & $\operatorname{High}(n=11)$ & \\
\hline Sex M/F (No \%) & $\begin{array}{l}15 / 6 \\
24 \cdot 6 / 9 \cdot 8\end{array}$ & $\begin{array}{l}19 / 10 \\
31 \cdot 1 / 16 \cdot 4\end{array}$ & $\begin{array}{c}8 / 3 \\
13 \cdot 2 / 4 \cdot 9\end{array}$ & $>0.05^{\star}$ \\
\hline Alive/dead (No \%) & $\begin{array}{l}16 / 5 \\
26 \cdot 2 / 8 \cdot 2\end{array}$ & $\begin{array}{l}13 / 16 \\
21 \cdot 3 / 26 \cdot 2\end{array}$ & $\begin{array}{l}2 / 9 \\
3 \cdot 3 / 14 \cdot 8\end{array}$ & (Not tested) \\
\hline Cell immunotype B/T (No \%) & $\begin{array}{l}20 / 1 \\
32 \cdot 8 / 1 \cdot 6\end{array}$ & $\begin{array}{l}29 / 0 \\
47 \cdot 6\end{array}$ & $\begin{array}{l}9 / 2 \\
14 \cdot 8 / 3 \cdot 2\end{array}$ & $>0.05^{\star}$ \\
\hline Clinical stage I + II/III + IV (No \%) & $\begin{array}{l}2 / 19 \\
3 \cdot 3 / 31 \cdot 1\end{array}$ & $\begin{array}{l}7 / 22 \\
11 \cdot 5 / 36 \cdot 0\end{array}$ & $\begin{array}{l}3 / 8 \\
4 \cdot 9 / 13 \cdot 2\end{array}$ & $>0.05^{\star}$ \\
\hline B symptoms A/B (No \%) & $\begin{array}{l}14 / 7 \\
23 \cdot 0 / 11 \cdot 5\end{array}$ & $\begin{array}{l}19 / 10 \\
31 \cdot 1 / 16 \cdot 4\end{array}$ & $\begin{array}{l}5 / 6 \\
8 \cdot 2 / 9 \cdot 8\end{array}$ & $>0.05^{\star}$ \\
\hline First complete remission yes/no (No \%) & $\begin{array}{l}16 / 5 \\
26 \cdot 2 / 8 \cdot 2\end{array}$ & $\begin{array}{l}19 / 10 \\
31 \cdot 1 / 16 \cdot 4\end{array}$ & $\begin{array}{l}4 / 7 \\
6 \cdot 6 / 11 \cdot 5\end{array}$ & $<0 \cdot 05^{\star}$ \\
\hline $\begin{array}{l}\text { Age in years (median) } \\
\text { Survival in months (median) } \\
\text { AgNORs (Mean SD) } \\
\text { Area of nuclei in } \mu \mathrm{m}^{2} \text { (Mean SD) } \\
\text { Relapse yes/no }{ }^{\star \star}(\text { No \%) }\end{array}$ & $\begin{array}{l}56 \\
29 \\
1 \cdot 54(0 \cdot 32) \\
17 \cdot 01(6 \cdot 27) \\
5 / 11 \\
12 \cdot 8 / 28 \cdot 2\end{array}$ & $\begin{array}{l}50 \\
19 \\
2.92(0.63) \\
21.47(6.08) \\
12 / 7 \\
30.9 / 17.9\end{array}$ & $\begin{array}{l}52 \\
8 \\
4 \cdot 57(0 \cdot 43) \\
26 \cdot 21(4 \cdot 94) \\
2 / 2 \\
5 \cdot 1 / 5 \cdot 1\end{array}$ & $\begin{array}{l}>0.05 \dagger \\
<0.001 \ddagger \\
<0.0001 \dagger \\
>0.001 \dagger \\
>0.05^{\star}\end{array}$ \\
\hline Length of remission in months (median) $)^{\star \star}$ & 37.5 & 25 & 14 & $<0.05 \ddagger$ \\
\hline
\end{tabular}

* $\chi 2$ test.

${ }_{\star \star}^{\star} \chi 2$ test.
${ }_{\star}$ The data show patients who achieved the first complete remission.

†Kruskal-Wallis non-parametric test.

$\ddagger$ Log-rank test. 


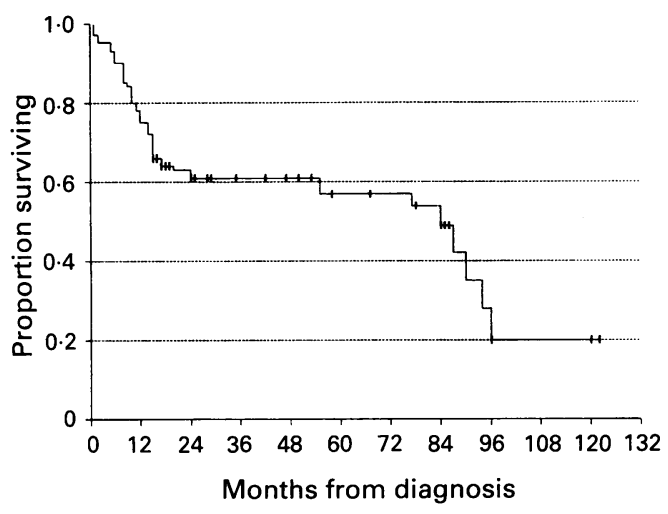

Figure 1 Actuarial survival in 61 patients with NHL (excluded data are noted). Survival probability after 10 years is 0.20 (95\% confidence interval limits: $0 \cdot 18,0 \cdot 23$ ).

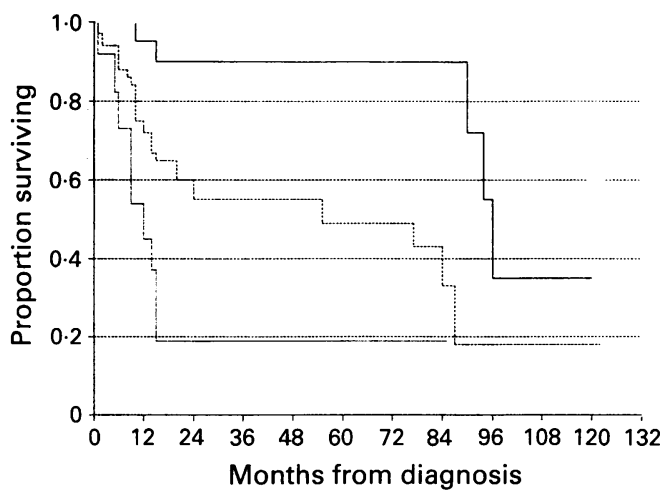

Figure 2 Actuarial survival of patients according to the working formulation of NHL continuous line-low grade NHL $(n=21)$; dashed line - intermediate NHL $(n=$ 29); dotted line- high grade NHL $(n=11)$. Survival probabilities after 10 years (with $95 \%$ confidence intervals) are $0.36(0.28,0.45), 0.17(0.12,0.22)$, and $0 \cdot 17(0 \cdot 09,0 \cdot 25)$, respectively.

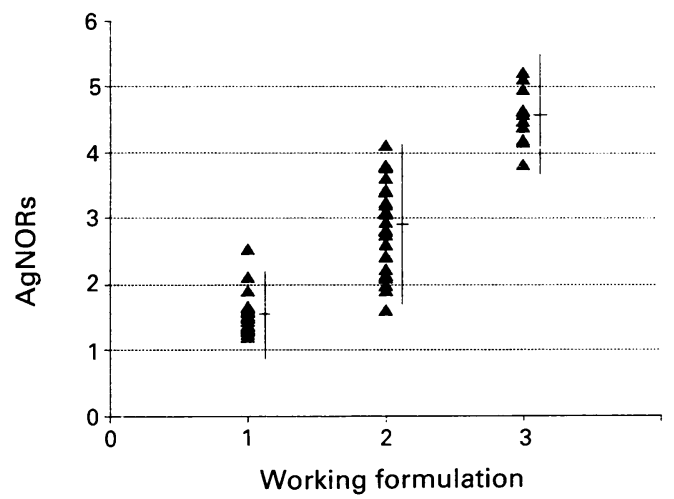

Figure 3 Scatter plot of nucleolar organiser regions (AgNORs) values by the working formulation of NHL $(1=$ low grade $(n=21) ; 2=$ intermediate $(n=29) ;$ and $3=$ high grade $(n=11)$ NHL). Each pair of data presented with a filled triangle (some data overlap). Mean $(1.96 S D)(95 \%)$

dently correlate with tumour grade and clinical categories. Table 2 contains exact values of $\mathrm{F}$ ratios from discriminant analysis and $\chi^{2}$ results from proportional hazard regression, together with exact values of designated probability, to confirm our findings.

Only the number of AgNORs per nuclei proved to be highly predictive for all the examined clinical categories (survival: $\chi^{2}=29.2, \quad \mathrm{p}<0.001 ;$ remission: $\mathrm{F}=13.4$, $\mathrm{p}=0.001$; length of remission: $\chi^{2}=6.8$, $\mathrm{p}<0.01$ ), as well as for the histological type of NHL $(F=132.9, p<0.001)$. Observed effect of the number of AgNORs per nuclei to overall survival and disease free survival (length of remission) is shown in table 3 with regression coefficients (b): $b=-24.91$ $(p<0.001)$ for overall survival and $b=-20.17(p<0.01)$ for disease free survival. Area of nuclei was associated slightly, but was not significant with the achievement of remission (table 2$)(p=0.054)$.

\section{Discussion}

The assessment of grading of NHL tissue is a complex but important procedure because treatment and prognosis are dependent on it. There have been attempts to facilitate grading with different methods, such as enzyme histochemistry, immunohistochemistry, morphometry, electron microscopy, DNA flow cytometry, and NOR enumeration in NHL tumour cells. For some of these variables grading has prognostic value. Crocker and $\mathrm{Nar}^{11}$ investigated the distribution of argyrophilic NOR sites in NHL and showed that a clear distinction was observed between high and low grade lymphomas according to the Kiel classification of NHL. To test a relation between ploidy and AgNOR number per cell, Crocker et $a l^{19}$ performed a DNA flow cytometric study on low and high grade NHL tissue and showed that there was a high correlation between the AgNOR count and percentage of $S$ phase cells and concluded that AgNOR number reflected cell proliferation. This idea was supported by studies which compared and correlated percentage of cells reacting with $\mathrm{Ki}-67$ proliferating cell markers and number of AgNORs per nuclei. ${ }^{20}$ Correlation between these investigated variables was remarkably good. Because the AgNOR method is cheap, quick, and less cumbersome than DNA flow cytometry and does not require frozen sections for staining with $\mathrm{Ki}-67$ monoclonal antibody, it would be of great interest to attempt a direct correlation between clinical survival and AgNOR count in patients with NHL. In this way this method would be highly promising for pathological and clinical use.

In this study we have assessed the clinicopathological correlation and the prognostic relevance of AgNOR number in a group of patients with NHL. The results listed in table 1 indicate that there was a significant difference between AgNOR number (fig 3), area of nuclei, achievement of complete remission, length of remission, and overall survival of patients with NHL. The association between AgNOR number and histological grade suggests that the determination of AgNOR number provides information about the grade of malignancy of NHL in the working formulation grading system. Mean number of AgNORs in high grade lymphomas was significantly greater than those in the intermediate and low grade groups. In the study by Crocker and $\mathrm{Nar}^{11}$ a significantly different distribution of mean number of AgNORs 
Table 2 Multivariate analysis of variables studies and their prognostic values

\begin{tabular}{|c|c|c|c|c|c|c|c|c|}
\hline \multirow[b]{2}{*}{ Parameter } & \multicolumn{2}{|c|}{$\begin{array}{l}\text { Histological type } \\
\text { (low, intermediate, } \\
\text { and high) }(n=61)\end{array}$} & \multicolumn{2}{|c|}{ Survival $(n=61)$} & \multicolumn{2}{|c|}{$\begin{array}{l}\text { Remission } \\
\text { CR and non-CR } \\
\text { group }(n=61)\end{array}$} & \multicolumn{2}{|c|}{$\begin{array}{l}\text { Length of remission } \\
\text { for patients } \\
\text { achieved }(n=39)\end{array}$} \\
\hline & $F$ & $p$ & $\chi^{2}$ & $p$ & $F$ & $p$ & $\chi^{2}$ & $p$ Valu \\
\hline $\operatorname{Sex}(M / F)$ & $2 \cdot 3$ & $0 \cdot 113$ & $1 \cdot 1$ & $0 \cdot 299$ & 0.0 & 0.953 & $1 \cdot 7$ & $0 \cdot 197$ \\
\hline Age & 0.2 & 0.818 & 0.3 & 0.597 & $0 \cdot 1$ & 0.817 & $0 \cdot 1$ & 0.799 \\
\hline AgNORs & $132 \cdot 9$ & $<0.001^{\star}$ & $29 \cdot 2$ & $<0.001^{\star}$ & $13 \cdot 4$ & $0.001^{\star}$ & $6 \cdot 8$ & 0.009 * \\
\hline Area of nuclei & 0.0 & 0.983 & 0.2 & 0.629 & 3.9 & 0.054 & $0 \cdot 4$ & 0.523 \\
\hline Clinical stage (I-II/III-IV) & 0.4 & 0.678 & 3.3 & 0.071 & 1.9 & 0.177 & 1.5 & $0 \cdot 229$ \\
\hline B symptoms (yes/no) & 0.3 & 0.739 & $2 \cdot 0$ & $0 \cdot 151$ & $3 \cdot 4$ & 0.072 & $1 \cdot 2$ & 0.273 \\
\hline Histological type & \multirow{2}{*}{\multicolumn{2}{|c|}{0.821}} & 0.2 & 0.623 & 1.4 & 0.240 & 0.0 & \\
\hline $\mathbf{R}^{2}$ & & & & 32 & \multicolumn{2}{|c|}{$0.190^{0.24}$} & \multicolumn{2}{|c|}{$0.196^{0.961}$} \\
\hline
\end{tabular}

$\mathrm{F}=\mathrm{F}$ ratio from multivariate discriminant analysis; $\chi^{2}=$ result from multivariate proportional hazard regression; $\mathrm{p}=$ probability for obtaining that variable in the prognostic model (only $p \leqslant 0.05$ was considered significant ${ }^{\star} ; R^{2}=$ the coefficient of multiple determination for factors ${ }^{\star}$ which significantly describe the model. $\mathrm{CR}=$ complete remission.

between two groups of patients with $\mathrm{NHL}$ according to the Kiel classification was found. We showed that this method allows NHL tissue to be differentiated into three groups of malignancy according to the working formulation. This study also showed that the three groups of NHL differed in the achievement of the first complete remission $(p<0.05)$ (table 1) and that only numbers of AgNORs predicted the achievement of remission ( $p<$ 0.001 ) (table 2). In the group of high grade NHL a high number of AgNORs was correlated with a poor response to treatment because only four patients achieved complete remission (table 1). These data might be confusing because one can expect that tumours with a larger proliferative activity (measured by AgNOR number) should be more sensitive to cytotoxic drugs. Similar results were reported by Cowan et $a l^{9}$ who showed that patients with a high proliferative index (measured by flow cytometry as a percentage of cells in $S$ and $G_{2} M$ phase of cell cycle) had a poor response to treatment. This could be the result of rapid repopulation of neoplastic cells between courses of chemotherapy and the increased probability of "resistant" clones in highly proliferative tumours. The authors concluded that patients with high proliferative tumours would be candidates for more intensive chemotherapy. We also found that three groups of patients showed a difference in the length of remission which was 33 months in the group of low grade NHL, 25 months in the intermediate grade group, and 14 months in the high grade group $(p<$ $0.05)$. Multivariate analysis showed that only AgNOR number was a prognostic variable for the length of remission in the group of patients who achieved the first complete remission. It is clear that patients with the lowest AgNOR number had the longest

Table 3 Influence of AgNORs on overall survival and disease free survival (length of remission)

\begin{tabular}{lllll}
\hline & AgNORs \\
\cline { 2 - 5 } & $b$ & $S E$ & $t(b=0)$ & $p$ Value \\
\hline $\begin{array}{l}\text { Overall survival } \\
\text { Disease free survival }\end{array}$ & -24.91 & $3 \cdot 22$ & $-7 \cdot 73$ & $<0.001$ \\
\hline $\mathrm{b}=$ estimated regression coefficient; $\mathrm{SE}=$ standard error, an \\
estimate of the precision of the regression coefficient; \\
$\mathrm{t}(\mathrm{b}=0)=t$ test value for testing hypothesis regression coeffi- \\
cient equals zero (hypothesis that AgNORs are independent \\
of survival); $\mathrm{p}=$ probability of obtaining hypothesis tested.
\end{tabular}

length of remission period, probably as a result of very slow repopulation of neoplastic cells because its proliferative activity was low. The association between these two variables was significant by regression coefficient $(b=-20 \cdot 17, p<0.01$ ) (table 3$)$. There have been no published reports describing the mutual influence of different variables on the length of remission in patients with NHL. The survival related relevance of the histological type of tumour is documented in figure 2 . In a multivariate analysis the mean AgNOR number was obviously related to the survival (table 2) (fig 2), with a high level of significance $(p<0.001)$. The observed effect was significant $(b=-24.91, p<0.001)$ (table 3$)$. Other investigated variables, such as sex, age, area of nuclei, clinical stage, and presence of B symptoms had no prognostic effects, even when investigated in relation only to survival and AgNOR number, using standard univariate models (results not shown). Unfortunately, we were not able to prove the same result in each tumour grade group according to the working formulation because the samples were too small for a multivariate approach.

This was a retrospective study and the patients did not receive uniform treatment protocols. AgNOR count was a very important and highly predictable factor of survival when included in multivariate analysis with other known prognostic factors. AgNOR number also differed within the three histological groups, as well as being associated with the length of remission and the response to treatment.

This new prognostic variable-mean AgNOR number per nuclei-should be assessed in future clinical studies to establish its clinical value, especially because it is simple, cheap, and available to every laboratory.

The technical assistance of Mrs Marija Rogina and Mrs Marija Skaleć is gratefully acknowledged.

1 Brittinger G, Bartles H, Common H, et al. Clinical and prognostic relevance of the Kiel classification in nonHodgkin's lymphomas. Results of a prospective multicenter study by the Kiel Lymphoma Study Group. Haematol Oncol 1984;2:269-306.

2 Fisher RI, Hubbard SM, De Vita VP, et al. Factors predicting long-term survival in diffuse mixed histiocytic or undifferentiated lymphoma. Blood 1981;58:45-51.

3 Kaneko Y, Rowley ID, Variakojis D, et al. Prognostic implicators at karyotype and morphology in patients with non-Hodgkin's lymphoma. Int $¥$ Cancer 1983;32: with non-

4 Koziner B, Little C, Passe S, et al. Treatment of advanced 
diffuse histiocyte lymphoma and analysis of prognostic variables. Cancer 1982;49:1571-9.

5 Warnke R, Miller R, Grogan T, Pederson M, Dieley J, Levy R. Immunologic phenotype in 30 patients with diffuse large-cell logic phenotype in 30 patients with dif293-300.

6 Rehn S, Glimelius B, Strang P, Sundstrom C, Tribukait B. Prognostic significance of flow cytometry studies in B-cell non-Hodgkin lymphoma. Haematol Oncol 1990; 8:1-12.

7 Wooldrige TN, Grierson HL, Weisenburger DD, et al. Association of DNA content and proliferative activity with clinical outcome in patients with diffuse mixed cell and large cell non-Hodgkin's lymphoma. Cancer Res 1988;48:6608-13.

8 Macartney IC, Camplejohn RS, Moris R, Hollowood K, Clarke D, Timothy A. DNA flow cytometry of follicular non-Hodgkin's lymphoma. I Clin Pathol 1991;44: 215-8.

9 Cowan RA, Harris M, Jones M, Crowther D. DNA content in high and intermediate grade non-Hodgkin's lymphoma-prognostic significance and clinicopathological correlations. Br 7 Cancer 1989;60:904-10.

10 Cole C, Rowe D, Delbridge L, Phillips J, Friedlander M Comparison of image analysis and flow cytometric determination of cellular DNA content. 7 Clin Pathol 1991;44:147-51.

11 Crocker J, Nar P. Nucleolar organizer regions in lymphomas. F Pathol 1987;151:111-9.

12 Crocker J, Egan MJ. Correlation between NOR sizes and numbers in Non-Hodgkin's lymphoma. $f$ Pathol 1988; 156:233-9.

13 The non-Hodgkin's lymphoma pathologic classification project. National Cancer Institute sponsored study of classification of non-Hodgkin's lymphomas. Cancer 1982;49:2112-35

14 Egan M, Ramsden K, Crocker J. Diagnostic significance of mean numbers of nucleolar organizer regions in benign and malignant transitional tumors of nose. Histopathology 1988;13:579-81.

15 Howat AJ, Giri DD, Wright AL, Underwood JCE. Silverstained nucleoli and nucleolar organizer region counts are of no prognostic value in thick cutaneous malignant melanoma. F Pathol 1988;156:227-32.

16 Siegel S, Castellan NJ Jr. Nonparametric statistics for the behavioral sciences. 2nd edn. Toronto: McGraw-Hill Book Company, 1988:191-200, 206-16.

17 Matthews DE, Farewell VT. Using and understanding medical statistics. 2nd edn. Sydney: Karger, 1988:67-87.

18 Number cruncher statistical system: Survival analysis reference manual, version, 5.5. Kaysville: Dr Jerry L Hintze, 1988:39-49.

19 Crocker J, Macartney JC, Smith PJ. Correlation between DNA flow cytometric and nucleolar organizer region data in non-Hodgkin's lymphomas. F Pathol 1988;154: 151-6.

20 Hall PA, Crocker J, Watts A, Stansfeld AG. A comparison of nucleolar organizer region staining and $\mathrm{Ki} 67$ immunostaining in non-Hodgkin's lymphoma. Histopathology 1988;12:373-81. 